\title{
PIERRRE BOURDIEU E AS REGRAS DO CAMPO LITERÁRIO
}

Vera Teixeira de Aguiar*

SÍNTESE - Este estudo apresenta as principais idéias de Pierre Bourdieu referentes à análise sociológica da literatura, quando discute as seguintes questões: as relações entre a literatura e a ciência, as possibilidades de análise sociológica da literatura, a definição do campo literário, as relações do campo literário com o campo econômico e os demais campos do espaço social, as relações de oposição no interior do campo, a análise das obras literárias considerando as relaçōes entre o código literário e os que se referem à vida cotidiana, a proposição de um estudo histórico da literatura, a crítica à análise imanente da literatura.

\begin{abstract}
This work presents Pierre Bourdieu's main ideas for a sociological investigation of literature, considering the following subjects: the relationships between literature and science, the possible sociological analyses of literature, the definition of the field of literature, the relationships of the field of literature, the economical field and the others, the opposition relationships in the field itself, the analysis of literary compositions; considering the relationship between the literary code and the way of daily life, a possibility of a historical approach of literature, the criticism of immanent analysis.
\end{abstract}

Ao propor uma abordagem sociológica da literatura, Pierre Bourdieu ${ }^{1}$ salienta a resistência dos estudiosos da área em aceitarem a leitura científica do objeto literário, por perceberem nessa atitude a morte do prazer estético. Para o autor, no entanto, tal posicionamento significa a manutenção de privilégios para os "iniciados", únicos capazes de captar o sentido transcendental e intangivel da obra artística, para o qual a sensibilidade do homem comum está despreparada. A análise científica do texto literário como produto de conhecimento humano fornece os instrumentos e os caminhos para a melhor compreensão de sua estrutura e funcionamento, o que vem a intensificar a experiência estética, ao invés de destruí-la.

Como a ciência é passivel de aprendizagem, seu domínio não se limita a uma casta específica, mas pode estender-se a camadas mais amplas da sociedade. Dessa forma, a literatura deixa de ser um bem seletivo, distintivo de classe, para democratizar-se entre todos os homens. Partindo desses pressupostos, Bourdieu dispõese a entender a gênese social do campo literário, os jogos de linguagem e de inte-

* Pontificia Universidade Católica do Rio Grande do Sul, PUCRS.

1 Bourdieu, Pierre. Les règles de l'art: genèse et structure du camp littéraire. Paris: Seuil, 1992.

\begin{tabular}{|l|l|l|l|l|l|}
\hline VERITAS & Porto Alegre & v. 41 & $n^{\circ} 162$ & Junho 1996 & p. 237-241 \\
\hline
\end{tabular}


resse e as apostas materiais e simbólicas que ali se realizam, de modo a desvendar melhor o papel da obra de arte como agente de comunicação inter-humana.

Para empreendimento de tal complexidade, o autor faz uma proposta de análise da literatura não só do ponto de vista estrutural e formal, mas de abrangência social (socioanálise, como denomina). Para exemplificar, vale-se das obras de Gustave Flaubert, $A$ educação sentimental e Madame Bovary, permitindo que se abstraia do exercício prático um modelo de abordagem textual sistemático e científico. Pode-se, assim, avaliar a dimensão da análise sociológica literária, segundo seus princípios. A leitura da obra de ficção, por essa ótica, centra-se na realidade social representada no texto através das personagens e suas ações, nos recursos estruturais e lingüísticos, que denotam as relações entre narrador e personagens, e na trajetória do autor, importando o lugar ocupado pela produção em foco.

A personagem, como elemento estruturador da seqüência narrativa, é descrita a partir da situação econômica e da posição social, dados nem sempre evidentes no relato e, por isso, passíveis de serem interpretados através de indícios deixados por detalhes (utensílios, assessórios, vestimentas, expressões, etc). O lugar que ocupa permite-lhe práticas e trocas sociais, todas elas configuradas como sua mobilidade possível nos pólos de poder político, econômico, social, cultural e literário. É necessário decifrar, por isso, as ambigüidades que denotam posições marcadas nos campos de lutas e revelam as intenções da personagem. A ação é circunscrita aos limites do espaço social por onde ela transita, uma vez que, segundo o plano do escritor, cada personagem tem uma fórmula geratriz.

A história desenvolve-se com as relações sentimentais dando uma ilusão de realidade e dissimulando os interesses de poder e de classe (e de transmissão do poder entre as gerações) que, verdadeiramente, regem as relações humanas. Assim, os sofrimentos submetem-se à dialética do ressentimento, como ambição frustrada e revolta submissa, pois todo o comportamento é subordinado às forças do poder. Para a progressão narrativa, ocorrem acidentes, isto é, colisões imprevistas de possibilidades sociais que mudam a estrutura da história, garantindo ao desfecho uma distribuição satisfatória dos papéis sociais e, por isso, a solução dos conflitos.

As estratégias de construção da obra conferem uma função especial ao narrador como aquele elemento que controla as relações das personagens e a interferência do mundo do autor no espaço fictício do texto. Através de recursos de linguagem e estilo (como discurso direto, indireto e indireto livre, diálogos, citações, descrições...), o narrador garante sua eqüidistância do objeto narrado, aproximando-se e afastando-se, segundo seus interesses de desvelar ou encobrir as intenções das personagens no jogo do poder. Para tal, vale-se também dos recursos do silêncio e, através dos não-ditos, deixa claras as razões das personagens em seus atos, toma posições e divulga simpatias e antipatias do próprio autor.

Se a obra de arte é uma representação simbólica da realidade, ela não reporta abertamente o posicionamento do autor. O jogo do narrador, no entanto, permite que se descubra na teia narrativa as opções daquele que correspondem, por seu turno, ao lugar que ocupa nas instâncias do poder. As revelações fornecidas são cotejadas com outras, advindas da observação da importância da obra na trajetória do autor, de modo a situá-la no campo literário. Uma leitura sociológica, pois, não 
rompe o charme da literatura, mas redescobre-o, ao possibilitar a compreensão do código usado pelo escritor para dar impressão de realidade ao real que o texto encobre.

Por campo literário Bourdieu entende o espaço social de produção, distribuição e recepção da literatura, incluindo aí todas as instituições encarregadas da dinâmica desses processos. Como tal, só adquire autonomia no século XIX, com o desenvolvimento da vida moderna, que the permite ligações estruturais cada vez mais complexas e autônomas, podendo desprezar as benesses de um mecenas (embora ainda viva um certo mecenato de Estado).

Inserida no modelo capitalista de economia, a literatura burguesa vem legitimar esse sistema, embora seus escritores transitem em grupos sociais diferenciados - mundanos, elitistas, boêmios. Nesse sentido, a imprensa tem papel preponderante, pois promove o alargamamento do público, quer pela publicação de obras, quer pelo painel que desenha da imagem da vida boêmia. Os escritores, por sua vez, compõem um grupo ambíguo, pois, se, por um lado, rompem com a burguesia ao criticá-la e apresentar alternativas de arte e de vida, de outro, buscam o reconhecimento social.

Por conta da complexidade das relações entre os campos literário e econômiCo, têm-se literaturas de intenções diversas - burguesa, puramente comercial; social, utilitária e engajada; arte pela arte, contestadora em sentido amplo. Salientase, aqui, que as possibilidades do artista puro estão diretamente relacionadas às vantagens econômicas de berço, isto é, tem mais chance de produzir literatura de valor estético reconhecido aquele que detém o capital econômico e cultural.

Para a criação literária, como de resto para a criação artística em geral, as escolhas possiveis estão condicionadas às práticas sociais e aos códigos vigentes. Para chegar à arte pura, o artista precisa dominar o estilo, usar a linguagem com a mesma desenvoltura com que se move na vida social, isto é, fundo e forma estão juntos, estilo literário é também estilo de vida.

Daí decorre que ao escritor é necessário o abandono da vida pequeno-burguesa, o conhecimento de um novo ethos, que vai lhe permitir entrecruzar discursos, construir personagens conflitantes, ampliar o horizonte social e cultural de seu texto. A emancipação do escritor, por sua autonomia no campo cultural, pode leválo a interferir no político, por exemplo, tentando impor leis particulares como se fossem universais. Nesse movimento, ele acaba sacrificando o literário, em favor de regras de outros campos, como acontece aos formalistas, aos estruturalistas e aos marxistas.

Como capital simbólico e econômico, a literatura participa da vida social lutando por legitimação. Nesse processo, interferem a tradição, o gosto e o mercado organizado. Uma obra é avaliada à luz de tudo aquilo que se produziu antes dela e foi valorizado pelo gosto socialmente hierarquizado. As distinções simbólicas são também econômicas, o que permite estabelecer uma homologia entre o espaço do autor e o do consumidor. Nesse momento, importa a tarefa das instituições literárias que garantem o mercado - editor, livreiro, distribuidor, animador - e são propiciadoras da construção de um perfil da obra, como pura ou comercial, quer dizer, as condições do mercado fazem o escritor e sua criação. 
O consumo da literatura depende diretamente do hábito de ler como um capital simbólico, prática adquirida no meio social, logo, não transcendente, inerente ou universal. Como detentor desse capital, o leitor estabelece com o texto um diálogo de igual para igual, desfazendo a imagem da obra como fetiche. A leitura interna, imanente, é acompanhada de uma outra, atrelada ao social, não havendo absolutização do texto, mas compreensão da homologia entre o conteúdo simbólico e os referentes do espaço de produção. Em outras palavras, o leitor busca no objeto literário as condições sociais de possibilidades e escolhas e as razões para a opção do autor.

Uma ciência das obras literárias, para Bourdieu, precisa dar conta de três operações: análise do campo literário no campo do poder e sua evolução, análise da estrutura interna do campo e sua evolução e análise da gênese das posições dentro do campo. O primeiro caso diz respeito à autonomia do autor, tanto mais independente quanto menos preso à demanda. A hierarquização do sucesso, por seu turno, é externa, a cargo do grande público, e interna, como reconhecimento dos pares. Assim, são escritores de sucesso os comerciais e as vanguardas reconhecidas, enquanto amargam o fracasso os fracos (comercialmente) e os malditos.

A rivalidade literária, portanto, diz respeito ao monopólio do poder de dizer com autoridade quem é escritor. As lutas dentro do campo legitimam, por um lado, aqueles que têm sucesso de vendas e, de outro, as vanguardas, que apontam para as possibilidades ainda não consagradas, mas com lugar social garantido.

As constatações acima confirmam as estreitas relações existentes entre o campo literário e os demais (e, especialmente, entre o campo literário e o social), uma vez que os novos autores só se impõem quando há condições externas favoráveis para isso. Suas obras tornam-se comerciais ou clássicas, segundo a qualidade social do público que as consome. Nessa perspectiva, uma obra-prima é aquela que atende aos interesses das classes letradas e sobrevive aos jogos de poder através dos tempos.

No entanto, se o meio de origem do escritor interfere em sua trajetória dentro do campo literário, ele não é, necessariamente, determinante de seu sucesso ou insucesso. Como as relações entre os campos são de homologia, e não de subordinação, há interferências de um a outro e, daí, a importância do tratamento da biobibliografia do autor, para compreensão dos fatores que contribuíram para seu alcance de um lugar definido dentro do campo literário.

Uma obra com grande repercussão comercial orienta-se no sentido da homogeneidade, fazendo confluir para ela os elementos dominantes do gosto de uma época. É, portanto, uma produção literária que confirma as tendências de seu tempo e, por isso mesmo, atrai as simpatias da massa de leitores comuns. Ao contrário, o texto de vanguarda é heterogêneo, contradizendo as normas dominantes e carregando em seu bojo o germe da dissolução. Capta as tendências renovadoras ainda em maturação, dando-lhes forma e rompendo, assim, com aquilo que é consagrado no momento de sua aparição. Altera, portanto, o código de leis internas vigente em sua época.

Importa, no entanto, salientar três aspectos nesse processo: primeiro, as rupturas são sempre parciais, pois, do contrário, a comunicação torna-se-ia inviável e o texto, irreconhecivel dentro do repertório literário; segundo, mesmo as negações 
mais profundas estão sobre o pano de fundo da ordem estabelecida dentro do campo, isto é, mudar as regras estabelecidas significa conhecê-las e levá-las em conta; por último, as escolhas do autor, em seu trabalho criativo, não são sempre e completamente conscientes. As três questões colocadas definem o processo de rompimento da vanguarda como relativo e resultante da interferência de fatores de vários campos que se cruzam. Do mesmo modo, essa efervescência multifacetada vai determinar a permanência ou não da nova obra.

Pela situação exposta, Bourdieu justifica o fracasso de uma análise da essência do texto literário, como querem os formalistas e os estruturalistas. O estudo imanente das características internas da literatura funciona como uma tentativa de universalização do particular, através do silêncio sobre as condições históricas e sociais das possibilidades de escolhas que o autor teve em sua tarefa produtiva. Em outras palavras, a investigação da essência da obra literária é sempre empobrecedora, porque desconsidera a multiplicidade de elementos de todos os campos que interagem no momento da criação e são codificados literariamente. Por outro lado, se a análise essencialista considera a experiência estética universal e única, ela transforma todas as propriedades particulares da obra (marcadas contextualmente) em privilégios, advindo daí a fama entre os pares.

A pesquisa sobre a história das instituições, do gosto, dos processos de produção, da distribuição e da consagração das obras, das categorias de percepção e avaliação oferece uma gama variada de informações novas sobre os textos literários que estabelecem elos de ligação entre a estrutura interna dos mesmos e a sociedade em que estão inseridos e com a qual dialogam, através dos tempos. Nesse sentido, a avaliação do papel das instituições de consumo importa para explicar as razões da leitura ou não das obras, os critérios de seleção adotados, os valores sociais defendidos segundo a qualidade dos públicos. Justificam-se, assim, o sucesso momentâneo de uma publicação e seu esquecimento, a grande receptividade de outra por apenas uma parcela do público e sua desconsideração pelas demais, e assim por diante (pois o que está em pauta é o jogo do poder).

Por esses caminhos, a ciência ilumina o estudo da literatura, ao trazer à tona todos os condicionamentos sociais que se fizeram presentes através da História e detectar as respostas dadas pelas manifestações literárias, codificadas e arranjadas estruturalmente. O saldo final é a melhor compreensão do diálogo das obras com a sociedade e a definição de seu papel como agente cultural. É mister, portanto, que se promova não só a recuperação das formas, mas dos estilos de vida e das lutas entre eles, chegando à historicização da produção e da recepção da literatura.

Não existe obra pura ou leitor puro, como pretendem as abordagens imanentistas. Assim, não se aspira à construção de uma visão de mundo homogênea, mas ao mapeamento dos conflitos existentes dentro do campo literário e daqueles entre o campo literário e o do poder, pela legitimação das produções, ou dentro dos outros campos, para o conhecimento das homologias existentes. Para isso, entendese a obra literária não como um produto acabado e estático, de domínio de uma casta privilegiada, mas como um organismo em constante atividade, agindo e reagindo, no seio da sociedade. 